\title{
The diagnosis and management of spontaneous coronary artery dissection - expert opinion of the Association of Cardiovascular Interventions (ACVI) of Polish Cardiac Society
}

\author{
Jacek Kądziela', Janusz Kochman², Marek Grygier³ , Ilona Michałowska4, Mariusz Tomaniak², Wojciech Wojakowski , \\ Aleksander Araszkiewicz' ${ }^{3}$ Maciej Dąbrowski', Michał Hawranek ${ }^{6}$, Zenon Huczek², Paweł Kralisz' , Jacek Kusa ${ }^{8}$, \\ Tomasz Roleder ${ }^{9}$, Andrzej Januszewicz ${ }^{10}$, Adam Witkowski', David Adlam ${ }^{11 *}$, Stanisław Bartuś12*
}

Reviewers: Maciej Lesiak ${ }^{3}$ Miłosz Jaguszewski ${ }^{13}$

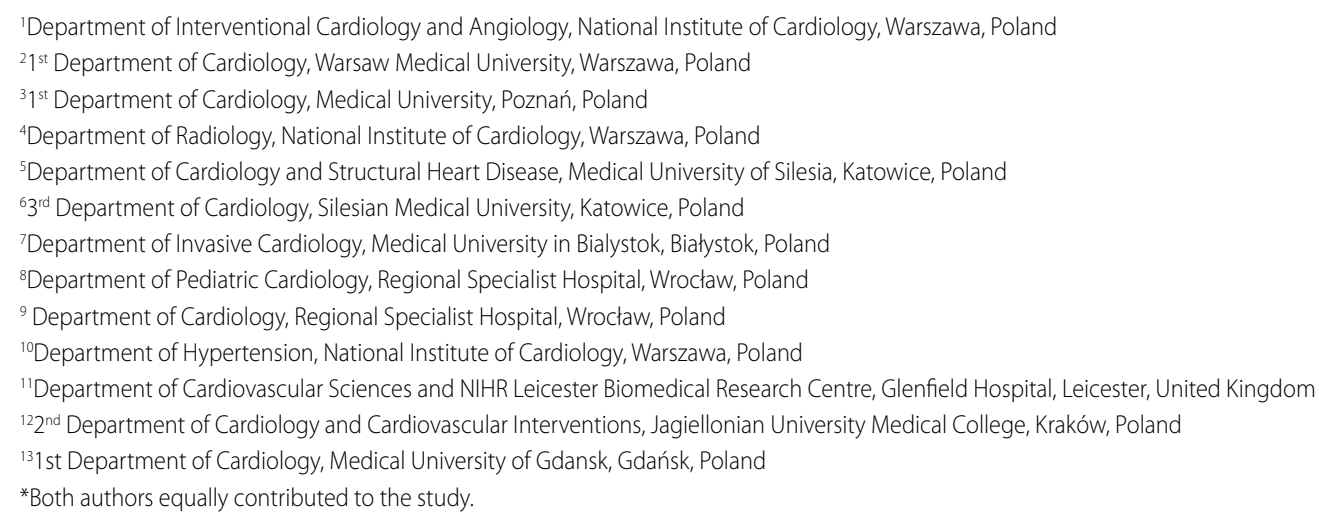

\section{Correspondence to:} Jacek Kądziela, MD, PhD, Department of Invasive Cardiology and Angiology, National Institute of Cardiology, Alpejska 42,

04-628 Warszawa, Poland phone: +48 223434272 e-mail:

kadziela@ikard.pl

Copyright by the Author(s), 2021

Kardiol Pol. 2021; 79 (7-8): 930-943; DOl: 10.33963/KP.a2021.0068

Received:

July 16, 202

Revision accepted: July 19, 2021

Published online: July 20, 2021

\section{INTRODUCTION}

Spontaneous coronary artery dissection (SCAD) has been recognized as a relatively uncommon disease for several years. The condition, although described, was poorly characterized in the era before intravascular imaging. As a result, women with SCAD were often misdiagnosed with an atheromatous acute coronary syndrome (ACS), MINOCA, or takotsubo cardiomyopathy. Increasing numbers of recent studies, including large registries, confirm that it should no longer be called a "rare" disease. These studies provided new information about the incidence, pathophysiological concepts, methods of diagnosis, and the treatment of this condition [1-9].

This paper aims to increase the awareness of SCAD among clinicians who take care of patients with acute coronary syndromes in the emergency room, through the catheterization laboratory, cardiology wards, to general practitioners. We present the recommendations regarding the identification of SCAD on angiography, the indications for the use of intravascular imaging, the methods of acute treatment, and long-term post-SCAD management. As prospective randomized trials are not available, these recommendations are based on retrospective analyses of series of patients or reflect experts' consensus.

\section{WHAT IS SCAD?}

Spontaneous coronary artery dissection is a non-atherosclerotic, non-traumatic, and non-iatrogenic disease of the coronary artery wall. It is a cause of the ACS and sudden cardiac death, especially among young and middle-aged women $[1,5,6,8]$. Pathophysiologically, two potential mechanisms for SCAD have been proposed. First, the "inside-out" mechanism, where an intimal tear allows blood from the vessel lumen to enter the artery wall leading to dissection and false lumen formation. Second, the "outside-in" mechanism assumes that the primary event is bleeding from microvessels (vasa vasorum) traversing the arterial wall. With both mechanisms, the intramural hematoma causes compression 


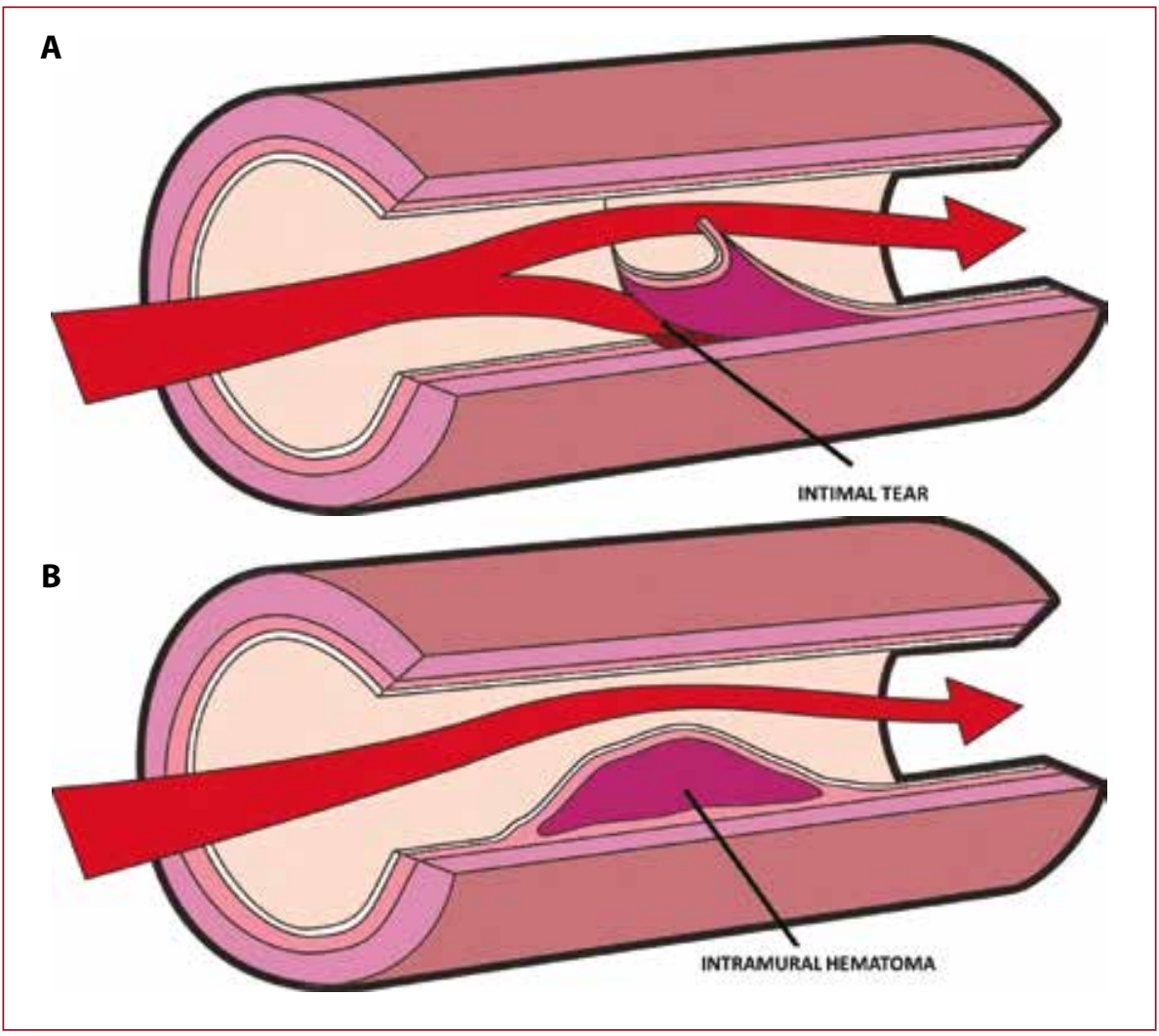

Figure 1. Pathophysiology of spontaneous coronary dissection (Images used courtesy of BeatSCAD, www.beatscad.org.uk)

Table 1. Spontaneous coronary artery dissection (SCAD) prevalence and baseline characteristics of patients — studies published since 2017

\begin{tabular}{l|c|c|c|c|c|c|c|c}
$\begin{array}{c}\text { Author } \\
\text { (year of publica- } \\
\text { tion) }\end{array}$ & $\begin{array}{c}\text { Number of SCAD } \\
\text { patients/number } \\
\text { of all ACS patients }\end{array}$ & $\begin{array}{c}\text { SCAD } \\
\text { prevalence, } \\
\%\end{array}$ & $\begin{array}{c}\text { SCAD prevalence } \\
\text { in women } \\
\text { S50 years of age }\end{array}$ & $\begin{array}{c}\text { Females, } \\
\%\end{array}$ & $\begin{array}{c}\text { STEMI/NSTEMI, } \\
\%\end{array}$ & $\begin{array}{c}\text { Multivessel } \\
\text { SCAD, \% }\end{array}$ & $\begin{array}{c}\text { Hyperten- } \\
\text { sion, \% }\end{array}$ & $\begin{array}{c}\text { Dyslipide- } \\
\text { mia, \% }\end{array}$ \\
\hline Motreff (2017) & $36 / 3224$ & 1.1 & 15.3 & 100 & $52.7 / 47.3$ & 18.2 & 27.3 & 10.9 \\
Meng (2017) & $21 / 60^{\mathrm{b}}$ & - & 35.0 & $100^{\mathrm{b}}$ & $57.1 / 42.9$ & 4.8 & 33.3 & NR \\
Abreu (2018) & $27 / 5002$ & 0.5 & $\mathrm{NR}$ & 81.4 & $37.0 / 55.5$ & 3.7 & 55.6 & 44.4 \\
Clare (2019) & $208 / 26598$ & 0.78 & $\mathrm{NR}$ & 88.9 & $19.7 / 85.5$ & 10.8 & 30.8 & 27.9 \\
Inohara (2020) & $322 / 68909$ & 0.5 & 6.6 & $100^{\mathrm{a}}$ & $\mathrm{NR}$ & $\mathrm{NR}$ & 58.7 & 40.1 \\
de Roeck (2020) & $27 / 102^{\mathrm{b}}$ & - & 26.5 & $100^{\mathrm{b}}$ & $51.9 / 40.7$ & 7.4 & 7.4 & 11.1 \\
Krittawong (2020) & $375 / 30427$ & 1.2 & $\mathrm{NR}$ & 64.3 & $\mathrm{NR}$ & $\mathrm{NR}$ & 54.7 & $\mathrm{NR}$ \\
\hline
\end{tabular}

anly women included; b Only women up to 50 years of age included.

Abbreviations: ACS, acute coronary syndrome; NR, not reported; NSTEMI, non-ST segment elevation myocardial infarction; STEMI, ST segment elevation myocardial infarction

of the true lumen resulting in compromised blood flow (Figure 1). Recent intracoronary imaging studies have shown that in a large proportion of SCAD cases, an intimal tear is not present or is preceded by intramural hematoma development, supporting the "outside-in"hypothesis as the predominant mechanism for SCAD [10-13].

\section{INCIDENCE, PRECIPITATING RISK FACTORS, COMORBIDITIES, AND CLINICAL PRESENTATION}

The true prevalence of SCAD remains unknown as this is still an underdiagnosed disease. In recently published studies, SCAD accounted for $0.3 \%-1.2 \%$ of all ACS cases [3, 14-16] (Table 1).

This condition affects predominantly young and middle-aged women (more than $70 \%$ of cases reported in sev- eral studies) [5]. The reported prevalence of SCAD in women below 50 years of age presenting with ACS ranges from 6.6 to $35 \%[14,16,17-22]$. No ethnic variations have been reported. The frequency of conventional risk factors for ischemic heart disease has often been considered minimal. Still, observational studies show these are certainly not negligible - hypertension was diagnosed in 18\%-57\% cases, hyperlipidemia in $10 \%-52 \%$, and smoking in $11 \%-57 \%$ [5, 8]. Indeed, in a recent analysis of more than 30000 patients presenting with ACS, SCAD patients $(n=375)$ were more often hypertensive than non-SCAD ACS patients [3]. This critical finding may potentially change the paradigm that SCAD afflicts predominantly healthy women.

The cause of SCAD remains unknown. The predominance in young and middle-aged women, together with the association with pregnancy (predominantly the $3^{\text {rd }}$ trimester) and 
the postpartum period, suggests a potential pathophysiological role of female sex hormones. However, the evidence of how this impacts mechanistically is still lacking [23]. Also, the following diseases or conditions were reported in case reposts or small case series, however, the potential causal relationship remains unproven: depression, hypothyroid, celiac disease, cryoglobulinemia, multiparity [5].

Spontaneous coronary artery dissection may have a genetic background in some cases (see Genetics section).

Among SCAD-related precipitating factors, extreme physical or emotional stress was most commonly identified [24-26]. Other potential factors, like Valsalva-type activities (sexual activity, weightlifting), use of recreational drugs (cocaine, amphetamine), high-doses of steroids, or caffeinated energy drinks binge, have been described in single-case reports $[25,27-33]$. The majority of patients with SCAD present with typical symptoms of ACS [1, 5, 6, 8]. However, in some cases, the pain may be atypical (back pain, pleuritic, positional, or burning), or dyspnea may be present. If it occurs in a young, healthy woman, the symptoms may be falsely interpreted as non-cardiac, leading to a delayed or even missed diagnosis of ACS. Thus, SCAD should always be considered in the differential diagnosis of ACS presentations in this low-risk population.

In approximately $8 \%$ of patients, SCAD-ACS can also present with cardiac arrest, ventricular arrhythmia, or cardiogenic shock [1, 34, 35]. Reported ECG findings at presentation vary in terms of different proportions of ST-elevation myocardial infarction (STEMI)/non-STEMI (NSTEMI), but mainly favoring NSTEMI $[8,19,21,36]$. In the largest cohort of a Canadian registry, including 750 patients, the proportion of NSTEMI/STEMI ACS subjects was $70 \%$ versus $30 \%$, respectively [1].

\section{DIAGNOSIS OF SCAD}

\section{Invasive coronary angiography}

Invasive coronary angiography constitutes the primary modality for the diagnosis of SCAD $[4,5]$. Coronary angiography should be performed with particular caution and using coaxial catheter alignment as an increased risk of catheter-induced iatrogenic dissections is observed in these patients [37, 38]. A Canadian study reported a 10-fold higher risk of iatrogenic dissection during angiography in SCAD patients as compared to non-SCAD angiography (2\% vs $0.2 \%$ ) [37].

The European Society of Cardiology (ESC) Position Paper differentiates four major angiographic types of SCAD, with type 2 further stratified into $2 \mathrm{a}$ and $2 \mathrm{~b}$ subtypes [5].

Type 1 is characterized by a double linear lumen with angiographic radiolucent 'flap' and contrast staining, resulting from a connection between true and false lumen (Figure 2A). While this is considered a pathognomonic SCAD presentation, it accounts only for one-third of SCAD patients $[4,26]$.

The remaining types have no double-lumen appearance and sometimes may be missed or misdiagnosed by an unaware or inexperienced operator.

Type 2 is visible as diffuse and predominantly smooth stenosis, typically located in the middle or distal segments
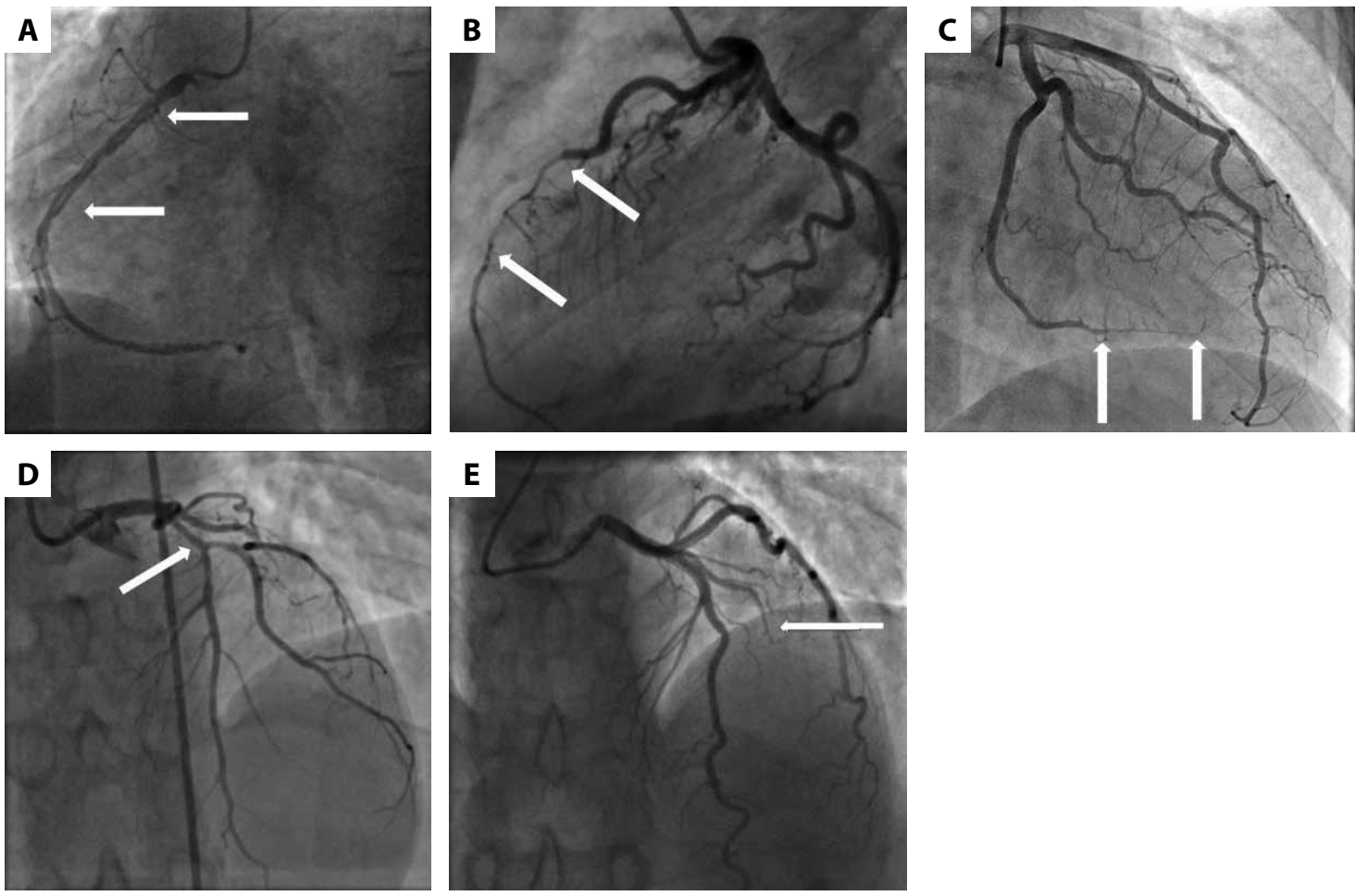

Figure 2. Angiographic types of spontaneous coronary artery dissection. A. Type 1. B. Type 2a. C. Type 2b. D. Type 3. E. Type 4 
of the artery. The narrowing is usually long with smooth borders (usually longer than $20 \mathrm{~mm}$ ) as a result of lumen compression by intramural hematoma with no communication between the false and true lumen and no penetration of contrast in the false lumen. It is the most frequently observed pattern reported in $55 \%-78 \%$ of all spontaneous dissections $[1,4,8,13]$. Type 2 is subdivided into Type 2a, in which the narrowing reconstitutes downstream into the normal vessel, and Type $2 \mathrm{~b}$, in which the stenosis extends to the most distal segment (Figure $2 \mathrm{~B}$ and $2 \mathrm{C}$ ). In most clinical scenarios, Type 2 SCAD can be recognized based on coronary angiography alone. However, in some cases, the final diagnosis may require additional intracoronary imaging to distinguish with certainty from atherosclerotic lesions.

Type 3 mimics focal atherosclerotic lesion and can be conclusively differentiated only with intracoronary imaging (Figure 2D). The stenosis is usually shorter, being caused by focal, non-propagated mural hematoma. It has been reported in approx. $10 \%$ of patients $[1,8]$.

Type 4 is defined as a total occlusion, usually in a distal segment of the artery (Figure $2 \mathrm{E}$ ). It can often only be recognized as SCAD when the flow is restored, either through coronary intervention or following vessel healing (at angiographic follow-up) and after exclusion of coronary embolism. This type is an addition to the original Yip-Saw angiographic classification of SCAD, in which only three types were distinguished [38].

The coronary distribution of SCAD has been widely investigated: the left anterior descending artery and its territory are the most commonly affected (in approximately half of the cases), the left main is less frequently involved (up to $4 \%$ of cases) $[21,36,39,40]$. The middle and distal segments of coronary arteries are predominantly affected (more than 90\%); in less than 10\%, the dissection is present in proximal parts of the major coronary artery or the left main $[26,29,30]$. Other angiographic features reported in SCAD patients included increased coronary tortuosity, reduced incidence or absence of atherosclerosis, coronary fibromuscular dysplasia, association of sites of dissection with myocardial bridging [5].

Multivessel SCAD is defined as simultaneous dissections occurring in more than one artery, without continuity, and is thus distinct from continuous dissection extending into the side branch. Multivessel SCAD occurs in 5\%-23\% of cases with no established risk factors $[11,36,39,40]$.

\section{Intravascular imaging}

Given that angiographic diagnosis is possible in most cases, intracoronary imaging is best reserved for ambiguous lesions $[6,37,41]$. This refers particularly to patients with deceptive Type 3 SCAD, which mirrors atherosclerotic disease, and selected patients with 2 type dissection. It might also facilitate percutaneous coronary interventions (PCl) optimization and confirmation of appropriate stent expansion and apposition [4,5].
Intravascular ultrasound (IVUS) allows for differentiation between atherosclerotic plaque and SCAD as it can depict the true and false lumen and the extent of intramural hematoma. Superior penetration ensuring complete visualization of the entire vessel wall without pressurized contrast injection are perceived as the main advantages of IVUS, compared with optical coherence tomography (OCT) [37, 42]. However, poor spatial resolution frequently limits the quality of imaging leaving significant diagnostic uncertainty and higher-resolution imaging is a better option if available.

With its superb spatial resolution (10-20 um), OCT enables detailed visualization of the intima-media complex, false lumen, presence of the thrombus, and fenestrations or connections between the true and false lumen. The benefits of OCT have to be weighed against the potential risk of further dissection propagation related to the high-pressure contrast injection required for good quality image acquisition (Figure 3 ). Thus, the modality should be limited to ambiguous lesions and to cases where imaging is required for clinical reasons (i.e., $\mathrm{PCl}$ optimization) Nevertheless, recent evidence suggests that $\mathrm{OCT}$ interrogation can be safely performed in SCAD patients $[10,12,16,42,43]$.

\section{Computed tomography coronary angiography (CCTA)}

Computed tomography is a widely used tool for coronary assessment in low- and intermediate-risk patients presenting with chest pain using the triple "rule-out" protocol. However, in many cases, SCAD may be missed or undetectable on CCTA because of its lower spatial resolution (particularly in distal segments) [44-46]. Thus, a negative CCTA result cannot exclude a diagnosis of SCAD in some patients. In the case of biomarker confirmed myocardial necrosis in young or middle-aged women presenting with ACS, coronary angiography should be always considered despite a negative CCTA result.

\section{ACUTE MANAGEMENT OF SCAD}

These recommendations on SCAD management are based solely on widely accepted consensus and observational data as there are currently no randomized trials comparing revascularization and conservative strategy [4-6].

A conservative approach to revascularization is recommended in most patients, considering that observational studies showed spontaneous healing of the vessel wall in most patients and a high complication rate in the subgroup treated with PCI [21, 37, 47-49]. In a recent angiographic follow-up study, restoration of vascular architecture was observed in $86.3 \%$ of patients. This ratio increased to $95.0 \%$ when repeated coronary angiography was performed at least 30 days after the index event [48].

Multiple studies published before 2018 reported a high $\mathrm{PCl}$ procedural failure rate, even in patients with preserved vessel flow, reaching $30 \%-50 \%$ with an increased incidence 


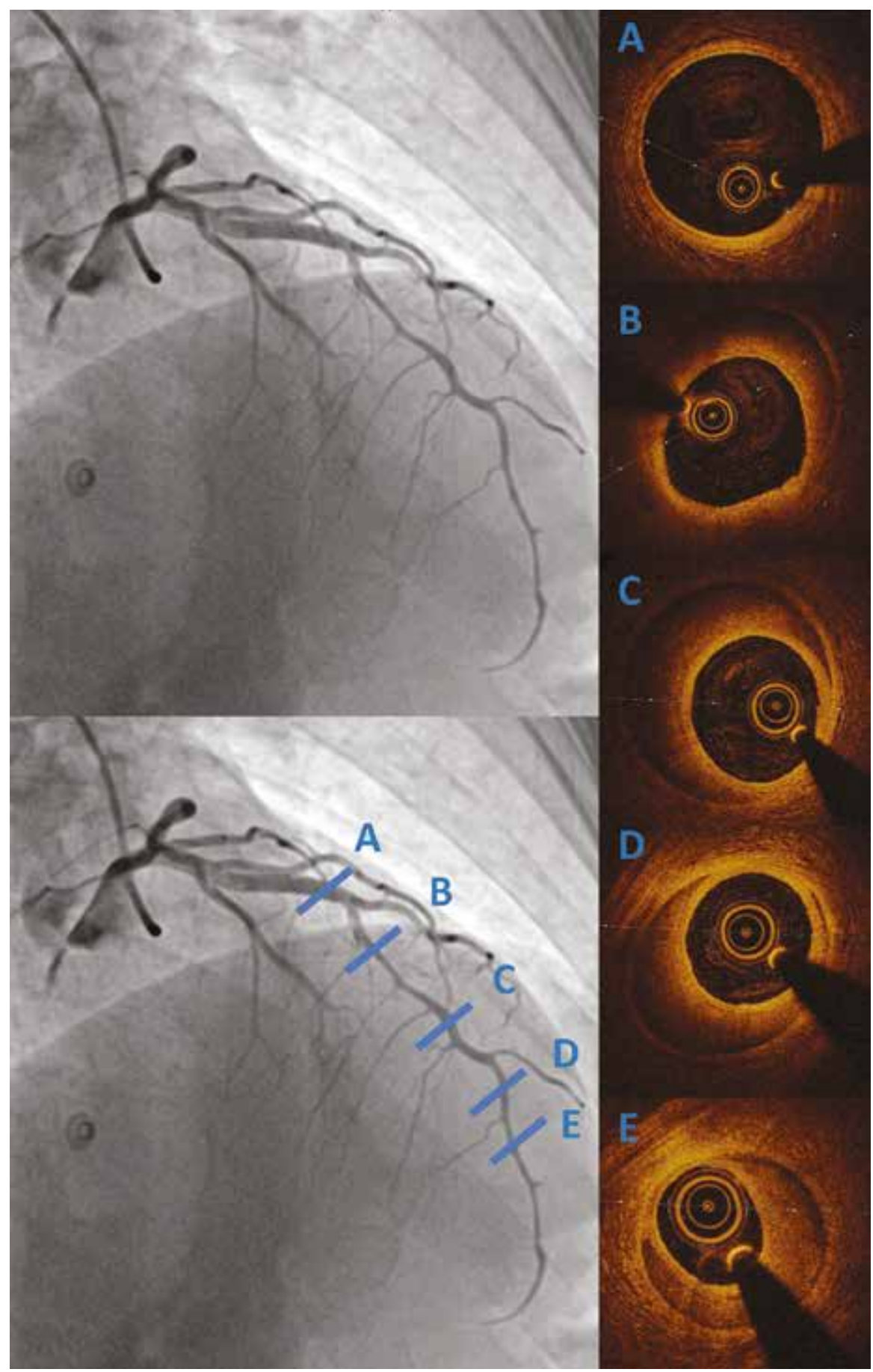

Figure 3. Optical coherence tomography in patient with SCAD. 49-year-old female without cardiovascular risk factors, hospitalized due to acute coronary syndrome without persistent ST segment elevation. Angiography depicted long smooth lumen narrowing in the mid and distal segment of left anterior descending (LAD) artery. Optical coherence tomography (OCT) revealed intramural hematoma propagating towards the distal segment of the artery (B-E). A. Healthy artery reference. SCAD type $2 b$ has been recognized

(up to $13 \%$ ) of emergency coronary artery bypass grafting $[26,36,39]$. For comparison, $90 \%$ of the conservatively managed group had an uneventful in-hospital course $[4,5]$. However, revascularization is still required in some high-risk patients, and this clinical presentation is not a very rare phenomenon. It was observed in $7.6 \%$ of patients in a recently presented large Canadian SCAD population [1]. Major $\mathrm{PCl}$ indications included ongoing ischemia, high-risk anatomy, i.e., proximal segment dissection of large epicar- dial arteries, and hemodynamic/cardiac rhythm instability $[4,5,50]$. The latest studies have provided more promising results of $\mathrm{PCl}$. An analysis of 144 United Kingdom patients treated percutaneously, including stenting in $72.4 \%$ of cases, plain old balloon angioplasty (POBA) in $21.1 \%$, and wiring in $6.4 \%$, was presented at the ESC Congress in 2020 [51]. The rate of all complications was high (38.8\%). Still, the rate of significant complications, defined as flow reduction in proximal/middle segment, stent extension 
into the left main artery, or iatrogenic dissection requiring $\mathrm{PCl}$ or coronary artery bypass grafting, was only $9 \%$, including predominantly (77\%) iatrogenic dissection. SCAD lesion length was associated with the presence of complications. Also, Lobo et al. [52] showed a $91 \%$ success rate of $\mathrm{PCl}$ in a relatively small group of 33 patients presented with STEMI. Those with revascularization were high-risk patients, more likely having shock, left main as a culprit lesion, proximal dissection, and initial flow grade 0 to 1 .

If $\mathrm{PCl}$ is required, special attention should be paid to catheter maneuvers to minimize the risk of iatrogenic dissection and ensure guidewire passage into the true lumen. The risk of false lumen propagation during stent deployment or side branch occlusion by hematoma propagation also needs to be considered. Therefore, the primary goal of revascularization should be the restoration of TIMI 3 flow with the least aggressive techniques possible, including POBA, selection of either a long stent to prevent hematoma propagation or focal intervention with short stent just to seal the entry 'tear' of the dissection $[25,39,48]$. The use of bioresorbable vascular scaffolds has been considered in relatively young patients and with a non-atherosclerotic, potentially healable, underlying condition [53]. A multicenter prospective study, including 15 high-risk SCAD patients who received 34 bioresorbable vascular scaffolds, showed very satisfactory late angiographic outcomes, with no significant restenosis and an excellent minimal luminal area and optimal coronary wall healing, as assessed after 2 years by CCTA [54]. Case reports have also described the use of cutting balloons to fenestrate the intimal-medial membrane and depressurize the false lumen and drain intramural hematoma [55].

In patients with cardiogenic shock, without improvement after $\mathrm{PCl}$, or with complicated $\mathrm{PCl}$, mechanical circulatory support devices like intra-aortic balloon pump, left ventricular assist device, or extracorporeal membrane oxygenation may be considered as a bridge to surgical revascularization or, if required, to heart transplantation [56-58].

Coronary artery bypass grafting may be considered in patients with left-main dissection or multivessel proximal SCAD when $\mathrm{PCl}$ is deemed to have a very high risk (due to high-risk anatomy) or in the case of $\mathrm{PCI}$ failure as a bailout strategy [4, 5]. Acute management of SCAD is summarized in Figure 4.

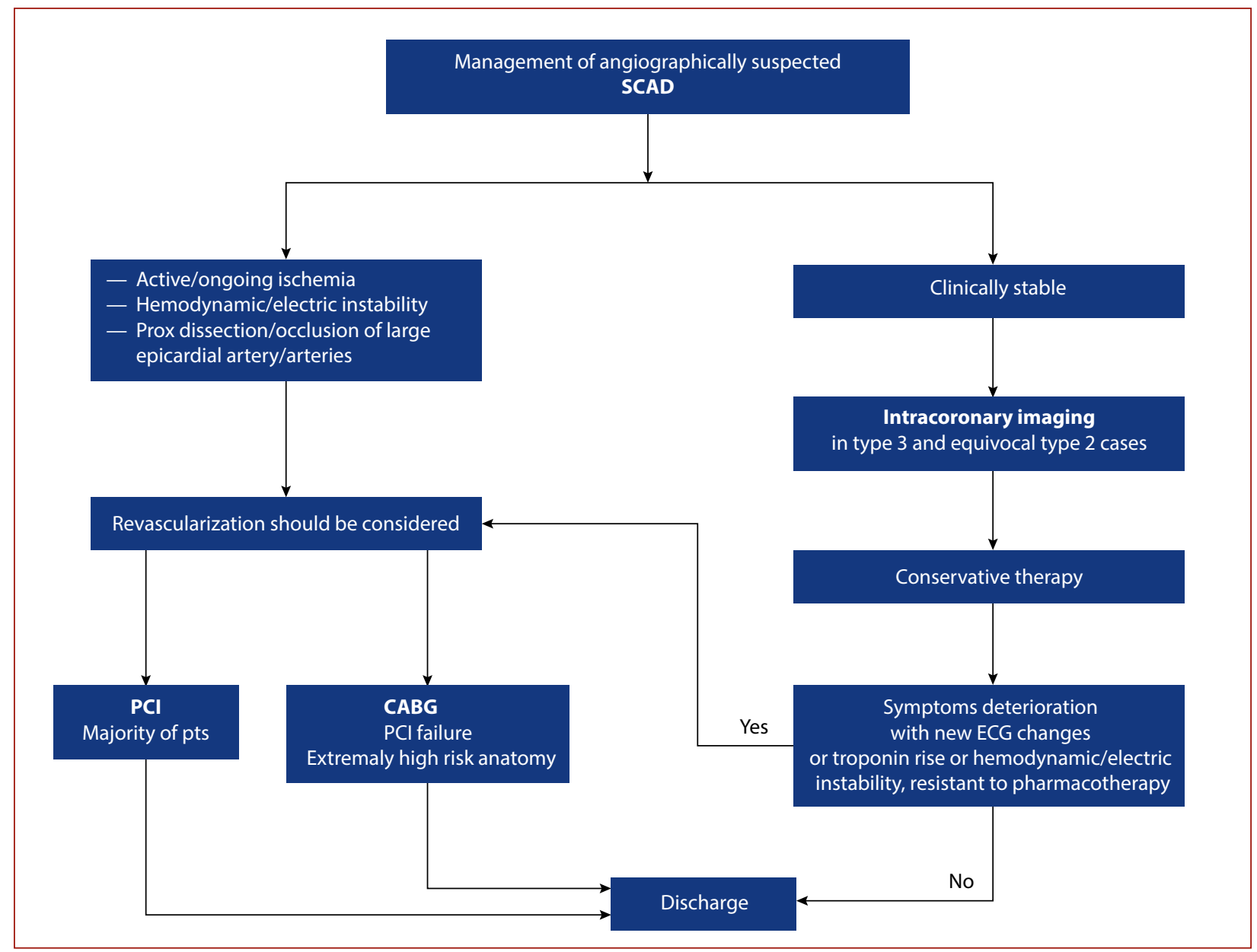

Figure 4. Acute management of spontaneous coronary artery dissection Abbreviations: prox, proximal; pts, patients 


\section{POST-SCAD MANAGEMENT}

Prognosis and post-SCAD chest pain management The prognosis of the majority of SCAD patients is good. In-hospital mortality differs between patients treated invasively (with worse initial presentation) and those managed conservatively. The in-hospital mortality of revascularized patients ranged from 0 to $3.5 \%[26,36,39]$. For comparison, in a Canadian registry, including 750 patients $(86.4 \%$ treated conservatively), in-hospital mortality was $0.1 \%$ ( 1 patient) and mortality between discharge and $30^{\text {th }}$ day was $0 \%$ [1]. However, it should be noted that 15 of 648 patients $(2.3 \%)$ initially treated conservatively required revascularization during the same hospitalization. Hence, longer hospitalization should be considered in conservatively managed patients.

Long-term mortality after SCAD ranges from 1.2 to $3.1 \%$ during the median follow-up period between 22 and 37 months $[14,25,36,39]$. In a recent study, 3-year survival after SCAD-related STEMI was $98 \%$ as compared to $84 \%$ after atheromatic STEMI [52].
Another analysis of 158 SCAD-survivors showed that the majority of patients have no or small infarctions and preserved ejection fraction as assessed in cardiac magnetic resonance imaging. Patients presenting with STEMI, TIMI $0 / 1$ flow, or multivessel SCAD, and those with connective tissue disorders were more likely to have larger infarcts [59]. Similar data regarding the infarct size have been reported from echocardiographic follow-up of 227 SCAD patients from the Canadian registry [60].

Considering the high percentage of spontaneous healing of conservatively treated SCADs and the potential risk for iatrogenic dissection, we do not recommend routine follow-up with coronary angiography in asymptomatic patients [48]. SCAD survivors frequently report chest pain, often for several months after discharge [61, 62]. Most chest pains are nonischemic, so for symptomatic patients after proximal or middle segment dissection, when ACS is excluded, CCTA is a reasonable diagnostic modality for vessel healing assessment (Figure $5 \mathrm{~A}$ ) or exclusion of instent restenosis (Figure 5B) [63, 64]. In the case of distal segments or small vessel dissections, CCTA may be an
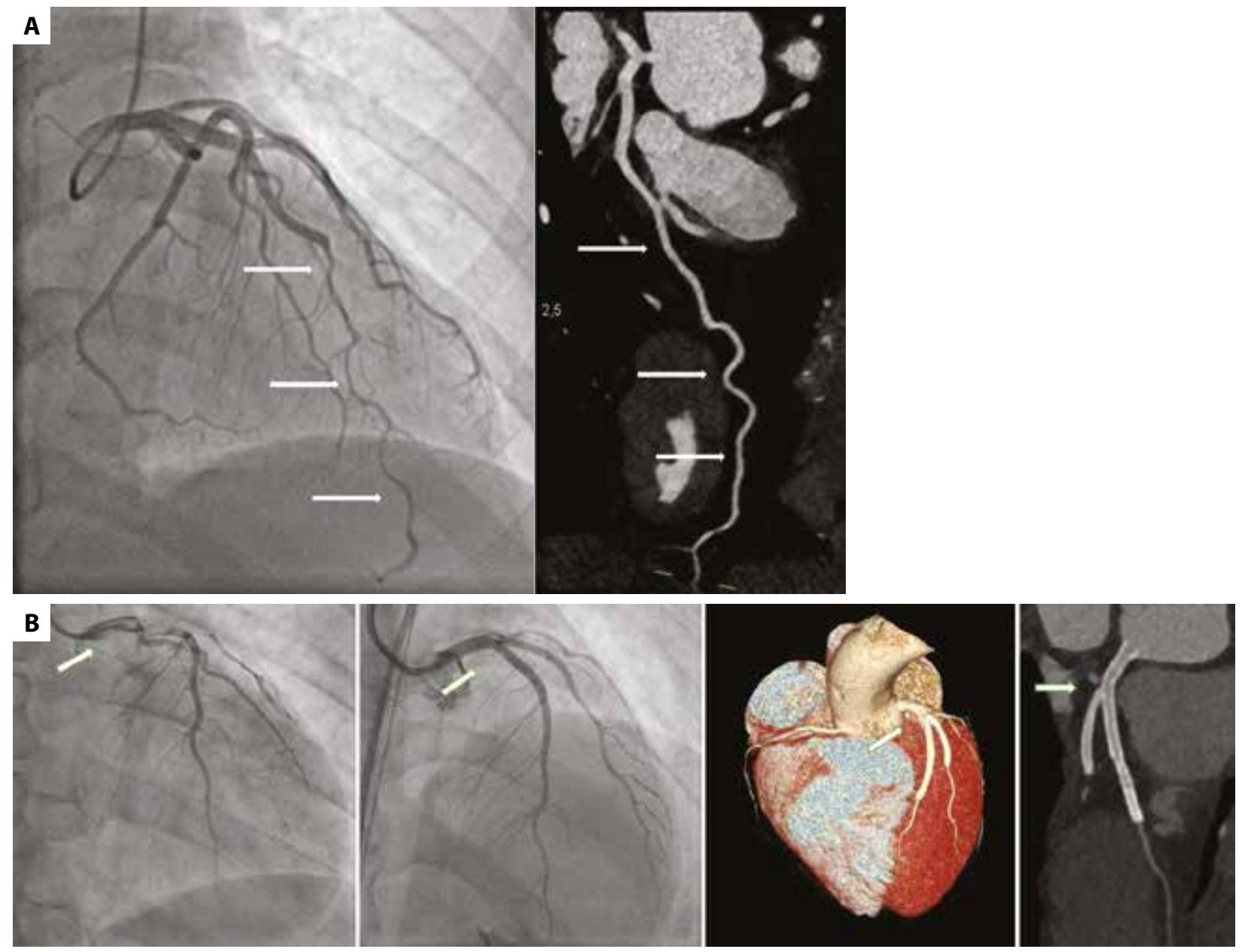

Figure 5. A. SCAD healing assessment using coronary computed tomography angiography: invasive coronary angiography with long type 2a SCAD in LAD (left), vessel healing confirmed in control CCTA (right); B. CCTA for in-stent restenosis exclusion. From left to right: initial angiography with left main SCAD; final angiography after stenting; CCTA during follow-up confirming favorable late result of $\mathrm{PCl}$ and no in-stent restenosis

Abbreviations: CCTA, computed tomography coronary angiography; LAD, left anterior descending; $P C l$, percutaneous coronary interventions; SCAD, spontaneous coronary artery dissection 
Table 2. Prevalence and predictors of SCAD recurrence

\begin{tabular}{|c|c|c|c|c|}
\hline $\begin{array}{c}\text { Author } \\
\text { (year of publication) }\end{array}$ & $\begin{array}{l}\text { Patients with recurrent } \\
\text { SCAD/all patients }\end{array}$ & Recurrence rate, $\%$ & Follow-up, months & Predictors of SCAD recurrence \\
\hline Eleid (2014) & $40 / 246$ & 16.2 & 20.5 & Tortuosity $\uparrow$ \\
\hline Nakashima (2016) & $14 / 63$ & $22.2^{\mathrm{a}}$ & 34 & NA \\
\hline Saw (2017) & $34 / 327$ & 10.4 & 37 & $\begin{array}{l}\text { Hypertension } \uparrow \\
\beta \text {-blockers use } \downarrow\end{array}$ \\
\hline Kok (2018) & $88 / 585$ & 15 & 31 & $N A^{b}$ \\
\hline Claire (2019) & $22 / 208$ & 10.6 & 56.4 & $\begin{array}{c}\text { Migraine } \uparrow \\
\text { Fibromuscular dysplasia } \uparrow\end{array}$ \\
\hline
\end{tabular}

aHalf of patients experienced recurrence of SCAD within 30 days after index event.

${ }^{\mathrm{b}}$ Recurrent chest pain within first 30 day after SCAD was more frequently reported in patients with migraine, however migraine was not related to 5-year SCAD recurrence

inadequate imaging method. In such cases, a functional test for ischemia may be considered. If abnormal, coronary angiography should then be considered.

\section{Recurrence of SCAD}

Recurrent SCAD is defined as the presence of new spontaneous dissection located either in another coronary segment or occurring more than $\mathbf{3 0}$ days after the initial episode. Recurrent SCAD reportedly occurs predominantly in a previously unaffected arterial segment [49].

The incidence of SCAD recurrence ranges from 10 to $22 \%$, with the mean time of observation between 20 and 56 months [14, 25, 36, 40, 49]. Analysis for potential predictors of recurrence is limited by the small numbers of patients with a second SCAD. One analysis of 216 SCAD survivors revealed that coronary tortuosity was statistically borderline associated with re-SCAD [65]. In another observational study, hypertension and $\beta$-blocker use were associated with increased and decreased risk of another SCAD, respectively [25]. As this study did not provide many details about the rate of blood pressure control or the type of drugs used, the results are hypothesis-generating rather than a guide to treatment and require confirmation in other observational studies and ultimately in a randomized trial [66] A further report of Clare et al., including 208 patients, found higher recurrence risk in patients with fibromuscular dysplasia and patients with a history of migraine headaches [2]. Statin or antiplatelet therapies were not associated with the increased risk. The results of recent studies on SCAD recurrence are summarized in Table 2.

\section{Medical therapy}

There are no available clinical trials assessing the efficacy of pharmacotherapy in SCAD survivors. Optimal medical treatment remains undetermined. However, as hypertension is one of the predictors of recurrent SCAD, optimal anti-hypertensive therapy is recommended, favoring $\beta$-blocker as a first-choice drug where tolerated. Following SCAD, an assessment of left ventricular systolic function with echocardiography or cardiac magnetic resonance imaging is mandatory to guide medical therapy and to evaluate potential indications for device implantation.
In patients with heart failure, guideline-based pharmacotherapy is recommended [67]. The benefit from statin use is unknown, so we do not recommend a statin in conservatively treated patients unless they have diabetes mellitus or other conditions requiring primary prevention. In patients after stenting or with vein grafts, statins may be considered asthey can delay neo-atherosclerosis formation, at least theoretically.

The recommended length of dual antiplatelet therapy (DAPT) in patients treated with stents is the same as after atherosclerotic ACS $[68,69]$. In patients treated conservatively, the benefit from the use of DAPT remains unproven. A pragmatic approach may be to use DAPT for at least 3 months in asymptomatic patients. If the vessel healing was confirmed on CCTA or angiography (if made for clinical reasons), DAPT could be stopped earlier. Clinical trials are needed to evaluate the balance between potential benefit or harm from long-term therapy with aspirin in conservatively treated patients with SCAD.

\section{Screening for fibromuscular dysplasia (FMD) and extracoronary vascular abnormalities (EVA)}

Fibromuscular dysplasia is an idiopathic, non-atherosclerotic, and non-inflammatory disease of medium-sized arteries characterized by abnormal cellular proliferation and distorted vessel wall architecture. It may affect all vascular beds, with renal and extracranial (carotid or vertebral) arteries most commonly affected and uncommon multivessel involvement (Figure 6) [70]. The typical morphological presentation includes two types of FMD: focal, which may occur in any part of the artery, and multifocal- with alternating areas of stenosis and dilation (called a 'string of beads'), which usually appears in middle and distal segments of the artery (Figure 6) [70].

The coexistence of SCAD and FMD was first reported in 2005 [71]. The prevalence of FMD in SCAD survivors reported in several studies ranged from $10 \%$ to $86 \%$, depending on the percentage of patients undergoing full screening [5]. Systematic evaluation substantially increases the sensitivity in FMD detection. In the largest cohort of the Canadian registry, 411 of 750 included patients were systematically evaluated, and FMD was found in $56.7 \%$ 

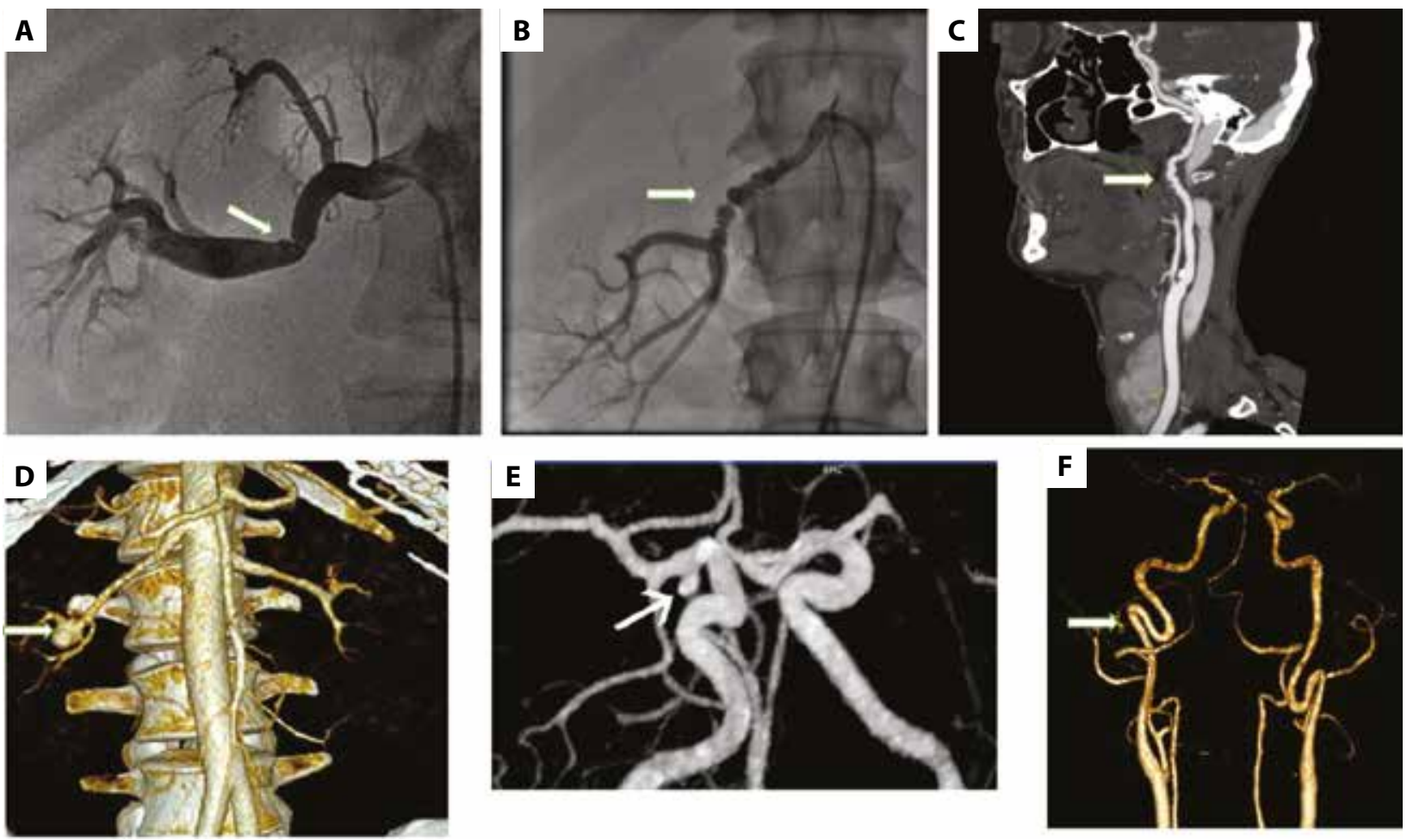

Figure 6. Extracoronary vascular abnormalities and comorbidities in patients with SCAD. A. Renal focal FMD. B. Renal multifocal FMD. C. Carotid FMD. D. Renal artery aneurysm. E. Carotid artery aneurysm. F. Tortuosity od carotid arteries

Abbreviations: FMD, fibromuscular dysplasia; SCAD, spontaneous coronary artery dissection

of them [1]. The prevalence of renal, cerebrovascular, and iliac/femoral FMD was $27.7 \%, 29.5 \%$, and $21.0 \%$, respectively. In a Mayo Clinic cohort, 335 of 585 included patients were screened and the frequency of FMD lesions was 58\% [72]. Carotid/cerebral FMD was detected in 28\%, body FMD in $52 \%$ of cases. FMD may also be more frequent in SCAD patients with a higher coronary tortuosity score [65]. In the ARCADIA-POL study, including 232 patients with FMD, systematic evaluation including "head-to-pelvis" computed tomography angiography resulted in detection of new FMD lesions in $34.1 \%$ of patients and previously undiagnosed vascular complications in $25 \%$ of subjects [73]. These findings require confirmation in SCAD-cohort observational studies.

The other EVAs found in patients with SCAD are aneurysms, dissections, and tortuosity, suggesting that SCAD may be the initial presentation of underlying arteriopathy (Figure 6) $[4,5]$. In the abovementioned Mayo Clinic, cohort EVAs were detected in $23 \%$ of patients [72]. The prevalence of cerebral aneurysms reported in multiple studies ranged from $7.1 \%$ to $22.5 \%[1,8,72,74]$. This finding may be clinically important as some aneurysms may require intervention or systematic follow-up depending on their size or morphology [75].

Therefore, the group of experts from ACVI recommends whole-body computed tomography or magnetic resonance angiography screening (from head to pelvis) for fibromuscular dysplasia and EVA presence in all SCAD survivors.

\section{Cardiac rehabilitation, psychotherapy}

In general, there is no contraindication to usual physical activity in patients after SCAD to avoid weight gain or deconditioning. However, patients should be advised to avoid prolonged high-intensity activities, highly competitive or contact sports, and activities performed to exhaustion (racing, boot camp) [6]. Exercise training should be low resistance with high repetitions to avoid strain or Valsalva maneuver. Cardiac rehabilitation is recommended in all patients as it is safe and psychologically beneficial. It reduces symptoms of chest pain, depression, and stress [61, 76]. SCAD survivors are at the risk of posttraumatic stress disorder, depression, and anxiety, which are associated with lower quality of life $[77,78]$. Given the prevalence and potential impact, screening and treatment for psychological distress are advised. Behavioral interventions targeted toward resilience training may be beneficial.

\section{Genetics}

Only a few reports of familial SCAD suggest it is not inherited disease in most cases $[79,80]$. Rare causal pathogenic genetic variants occur in a minority of SCAD patients, mostly associated with known concomitant connective tissue diseases, like Ehlers-Danlos, Marfan, Loeys-Diez syndrome, or polycystic kidney disease [5].

Recently, the first common genetic variant for SCAD has been identified. In the largest study conducted, including 1055 SCAD patients and 7190 case controls, the authors found an association between rs9349379 genotype of 
PHACTR1/EDN1 (phosphatase and actin regulator 1) gene on chromosome $6 q 24$ and the incidence of SCAD [81]. Rs9349379-A allele was related to the increased risk of SCAD. This genotype was also associated with other vascular diseases, including FMD, coronary artery disease, migraine, and cervicocerebral artery dissection in previous reports [82-85].

In another report, evaluating 667 women with SCAD and 1477 female controls, the authors from Mayo Clinic identified 5 risk loci associated with SCAD, including previously described locus (1q21.3; 6p24.1; 12q13.3; 15q21.1 and 21q22.11). The alternative alleles of 3 of them have also been reported to be linked with atherosclerotic coronary artery disease. It suggests an opposite susceptibility to coronary atherosclerosis vs dissection [86].

These findings were confirmed in another trial evaluating 270 SCAD cases and 5263 controls. The authors also identified the rs12740679 allele at chromosome 1q21.2, implicating the extracellular matrix protein-encoding gene ADAMTSL4, to be significantly associated with SCAD. Moreover, the previously reported chromosome 6p24.1 PTACTR1 locus (rs9349379) and the 12q13 LRP1 locus (rs11172113) were also associated with the risk of SCAD in the meta-analysis of the genome-wide SCAD discovery and replication results. Interestingly, all three loci have been described in association with migraine headaches. The authors developed and tested a genetic risk score and demonstrated not only the association with SCAD occurrence but also opposing risks of atherosclerotic vs SCAD-related myocardial infarction [87].

In a very recent British genome sequencing study including 476 SCAD survivors and 13722 controls, pathogenic or likely rare pathogenic variants were detected in 3.5\% of SCAD cases in 7 genes (PKD1, COL3A1, SMAD3, TGFB2, LOX, MYLK, and YY1AP1, with the highest association of the PKD1 gene with SCAD [88]. The results strengthen the overlap between SCAD and renal and connective tissue disorders. More studies are needed to confirm this finding.

So, at present, the group of experts does not recommend routine genetic screening. It can be considered in individuals with suspicion of connective tissue disease, extensive arteriopathies, or a strong family history of arteriopathies.

\section{Pregnancy after SCAD and contraception}

The risk of SCAD recurrence during pregnancy following a prior SCAD is poorly understood. Recently, the results of 636 women, including 23 patients who became pregnant (32 pregnancies) after SCAD, were published [89]. In the overall cohort, recurrent SCAD occurred in 122 patients. The study did not find evidence for an increased risk of SCAD recurrence in patients who became pregnant after SCAD when compared with women who did not experience pregnancy after an episode of SCAD. However, the results are limited by the small total number of women with pregnancy after SCAD, so should be interpreted with caution. So any decision on planning pregnancy should be carefully discussed with the pregnancy heart team, taking into account many aspects like left ventricular ejection fraction, maternal age, risk of recurrence, comorbidities, and teratogenic medications. In general, planned pregnancy is not contraindicated, but this decision should be individualized. Unplanned pregnancy should be avoided, and effective secure contraception is therefore important. Non-hormonal contraception is recommended such as non-hormonal intrauterine device or surgical sterilization of the patient or partner may also be a reasonable option. If hormonal contraception is required, despite the lack of studies in SCAD patients, highly effective progesterone-based approaches are preferable, including the long-acting subdermal levonorgestrel implant or levonorgestrel-releasing intrauterine device [90].

\section{PREGNANCY-ASSOCIATED SCAD (P-SCAD)}

The incidence of P-SCAD, assessed in a population-based cohort study including 4.3 million pregnancies, was 1.81 per 100000 [91]. The following overlapping mechanisms associated with pregnancy were hypothesized to have an etiological role in P-SCAD [92]: (1) increased cardiac output with secondary increased arterial shear stress; (2) excess progesterone leading to the loss of normal corrugation of elastic fibers, a decrease in acid mucopolysaccharide ground substance and weakening the tunica media; (3) excess estrogen facilitating matrix metalloproteinases release leading to cystic medial necrosis and lack of vasa vasorum structural support; (4) impaired collagen synthesis in the peripartum period.

P-SCAD is a common cause of ACS during pregnancy and the postpartum period, reaching up to $10 \%$ of all such ACS events [93, 94]. Chronic hypertension, lipid profile abnormalities, chronic depression, and history of migraine were associated with an increased risk for P-SCAD in one study [91].

P-SCAD patients are usually characterized by a more severe clinical course, including a higher risk of cardiac arrest, ventricular arrhythmia, and cardiogenic shock. This results from increased left mainstem involvement and multivessel dissection [23, 92, 95]. Multivessel involvement supports the hypothesis of generalized arterial wall changes under hormonal changes during pregnancy. STEMI ACS is diagnosed using ECG in approximately $60 \%$ of P-SCAD patients. The long-term prognosis after P-SCAD may worsen as the left ventricle ejection fraction is lower than in patients with SCAD not related to pregnancy; they also require implantable cardiac devices more frequently [23]. On the other hand, the risk of SCAD recurrence is comparable to other SCAD patients [23].

\section{FILLING THE GAPS AND GLIMPSE INTO THE FUTURE}

We presented recommendations on the diagnosis and management of spontaneous coronary artery dissection. Many questions, like the underlying pathophysiology, the 
Table 3. Summary of recommendations in SCAD management

DIAGNOSIS
SCAD should always be considered in the differential diagnosis of ACS
presentations, particularly in the low-risk population of young and middle
-aged women
Invasive coronary angiography remains the gold standard for the diagno-
sis of SCAD but should be performed with caution due to the increased
risk for iatrogenic dissection
CCTA made in triple "rule-out" protocol may be false negative in SCAD pa-
tients. In case of confirmed myocardial necrosis in young or middle-aged
women presenting with ACS, coronary angiography should be considered
despite negative CCTA result
Intravascular imaging (preferentially OCT) is recommended in 2 primary
clinical scenarios: ambiguous angiographic lesions, mainly type 3 as this
is indistinguishable from atherosclerotic lesion, and in selected patients
with type 2, especially when the clinical profile is not indicative for high
atherothrombotic risk

\section{TREATMENT}

Conservative management should be a default strategy for low-risk patients with NSTEMI, maintained coronary flow and more distal dissection since spontaneous healing of the vessel wall is observed in the majority of patients and coronary revascularization is associated with an increased risk of complications

Coronary revascularization, preferentially $\mathrm{PCl}$, is recommended in high-risk clinical and angiographic scenarios, including ongoing ischemia related to large vessel dissection, proximal dissection, hemodynamic or electrical instability

Coronary artery bypass grafting is recommended in patients with left-main dissection or multivessel proximal SCAD when $\mathrm{PCl}$ is considered to have a very high risk or in case of $\mathrm{PCI}$ failure as a bailout strategy

\section{POST-SCAD MANAGEMENT}

Optimal blood pressure control in hypertensive patients is recommended for secondary prevention of SCAD recurrence, with $\beta$-blocker preference as a first-choice drug, if not contraindicated

An assessment of left ventricular systolic is mandatory to guide medical therapy and to assess potential indications for device implantation. Guidelines-guided heart failure pharmacotherapy is recommended, if present after SCAD occurrence

The recommended length of dual antiplatelet therapy (DAPT) in patients treated with stents is the same as after atherosclerotic ACS. In patients treated conservatively, we advise using DAPT for at least 3 months in asymptomatic patients

For symptomatic patients after proximal or middle segment dissection, when ACS is excluded, CCTA is a reasonable modality for vessel healing assessment or in-stent restenosis exclusion. In the case of distal segments or small vessel dissections, CCTA may be an inadequate imaging method, and functional tests detecting ischemia are recommended. If they are abnormal, coronary angiography should be considered if revascularization is feasible and may be beneficial

Screening for fibromuscular dysplasia and the presence of extracoronary vascular abnormalities using "head-to-pelvis" CCTA arterial imaging is recommended

Usual physical activity is not contraindicated. Prolonged high-intensity activities, highly competitive or contact sports and activities performed to exhaustion should be avoided. Screening and treatment for psychological distress are strongly advised

The decision on planning pregnancy should be carefully individualized and discussed with the pregnancy heart team. Non-hormonal contraception is recommended for avoiding unplanned pregnancy - surgical sterilization may be a reasonable option. If hormonal contraception is required highly effective mono-hormonal contraception should be used, including the long-acting subdermal levonorgestrel implant or levonorgestrel-releasing intrauterine device

Routine genetic screening is not recommended. It can be considered in individuals with suspicion of connective tissue disease, aneurysm presence, or a family history of arteriopathies

Abbreviations: ACS, acute coronary syndrome; CCTA, computed tomography coronary angiography; NSTEMI, non-ST segment elevation myocardial infarction; OCT, optical coherence tomography; $\mathrm{PCl}$, percutaneous coronary interventions; $\mathrm{SCAD}$, spontaneous coronary artery dissection role of female sex hormones in the pathogenesis, the role and optimal duration of antiplatelet therapy, the identification of recurrence risk factors, the use of $\beta$-blockers, statins, or other potential secondary prevention drugs remain unresolved. The ESC has designed and just opened the European registry of SCAD survivors, including both prospective and retrospective subjects. Collecting data from $>1000$ patients will increase our knowledge and understanding of this mysterious disease. In Poland, the registry is coordinated by the National Institute of Cardiology, Warsaw. More information is available by e-mail: scad@ikard.pl

All recommendations presented in this document are summarized in Table 3.

\section{Article information}

Conflict of interest: $D A$ has received grant funding for SCAD research from BeatSCAD, the British Heart Foundation (BHF) [PG/13/96/3060], the National Institute for Health Research (NIHR) rare disease translational collaboration and the Leicester NIHR Biomedical Research Centre. Dr Adlam has received funding to support a clinical research fellow from Abbott vascular. He has also received funding from Astra Zeneca inc. for unrelated research and has conducted unrelated consultancy for GE inc.

Open access: This article is available in open access under Creative Common Attribution-Non-Commercial-No Derivatives 4.0 International (CC BY-NC-ND 4.0) license, allowing to download articles and share them with others as long as they credit the authors and the publisher, but without permission to change them in any way or use them commercially. For commercial use, please contact the journal office at kardiologiapolska@ptkardio.pl.

How to cite: Kądziela J, Kochman J, Grygier M et al. The diagnosis and management of spontaneous coronary artery dissection - expert opinion of the Association of Cardiovascular Interventions (ACVI) of Polish Cardiac Society. Kardiol Pol. 2021; 79(7-8): 930-943, doi: 10.33963/KP.a2021.0068

\section{REFERENCES}

1. Saw J, Starovoytov A, Humphries K, et al. Canadian spontaneous coronary artery dissection cohort study: in-hospital and 30-day outcomes. Eur Heart J. 2019; 40(15): 1188-1197, doi: 10.1093/eurheartj/ehz007, indexed in Pubmed: 30698711.

2. Phan D, Clare R, Duan L, et al. Characteristics and clinical outcomes of patients with spontaneous coronary artery dissection. J Am Heart Assoc. 2019; 8(10): e012570, doi: 10.1161/JAHA.119.012570, indexed in Pubmed: 31084345

3. Krittanawong C, Kumar A, Virk HU, et al. Recurrent spontaneous coronary artery dissection in the United States. Int J Cardiol. 2020; 301: 34-37, doi: 10.1016/j.ijcard.2019.10.052, indexed in Pubmed: 31757645.

4. Hayes SN, Tweet MS, Adlam D, et al. Spontaneous coronary artery dissection: JACC state-of-the-art review. J Am Coll Cardiol. 2020; 76(8): 961-984, doi: 10.1016/j.jacc.2020.05.084, indexed in Pubmed: 32819471.

5. Adlam D, Alfonso F, Maas A, et al. Writing Committee. European Society of Cardiology, acute cardiovascular care association, SCAD study group: a position paper on spontaneous coronary artery dissection. Eur Heart J. 2018; 39(36): 3353-3368, doi: 10.1093/eurheartj/ehy080, indexed in Pubmed: 29481627.

6. Hayes SN, Kim ESH, Saw J, et al. Spontaneous coronary artery dissection: current state of the science: a scientific statement from the American Heart Association. Circulation. 2018; 137(19): e523-e557, doi: 10.1161/CIR.0000000000000564, indexed in Pubmed: 29472380. 
7. Gad MM, Mahmoud AN, Saad AM, et al. Incidence, clinical presentation, and causes of 30-day readmission following hospitalization with spontaneous coronary artery dissection. JACC Cardiovasc Interv. 2020; 13(8): 921-932, doi: 10.1016/j.jcin.2019.12.033, indexed in Pubmed: 32327089.

8. García-Guimaraes M, Bastante T, Macaya F, et al. Spontaneous coronary artery dissection in Spain: clinical and angiographic characteristics, management, and in-hospital events. Rev Esp Cardiol (Engl Ed). 2021; 74(1): 15-23, doi: 10.1016/j.rec.2020.04.002, indexed in Pubmed: 32418854.

9. Kim ESH. Spontaneous coronary-artery dissection. N Engl J Med. 2020; 383(24): 2358-2370, doi: 10.1056/NEJMra2001524, indexed in Pubmed: 33296561.

10. Jackson R, Al-Hussaini A, Joseph $\mathrm{S}$, et al. Spontaneous coronary artery dissection: pathophysiological insights from optical coherence tomography. JACC Cardiovasc Imaging. 2019; 12(12): 2475-2488, doi: 10.1016/j. jcmg.2019.01.015, indexed in Pubmed: 30878439.

11. Waterbury TM, Tweet MS, Hayes SN, et al. Early natural history of spontaneous coronary artery dissection. Circ Cardiovasc Interv. 2018; 11(9): e006772, doi: 10.1161/CIRCINTERVENTIONS.118.006772, indexed in Pubmed: 30354594.

12. Alfonso F, Paulo M, Gonzalo N, et al. Diagnosis of spontaneous coronary artery dissection by optical coherence tomography. J Am Coll Cardiol. 2012; 59(12): 1073-1079, doi: 10.1016/j.jacc.2011.08.082, indexed in Pubmed: 22421300.

13. Paulo M, Sandoval J, Lennie V, et al. Combined use of OCT and IVUS in spontaneous coronary artery dissection. JACC Cardiovasc Imaging. 2013; 6(7): 830-832, doi: 10.1016/j.jcmg.2013.02.010, indexed in Pubmed: 23747066.

14. Nakashima T, Noguchi T, Haruta S, et al. Prognostic impact of spontaneous coronary artery dissection in young female patients with acute myocardial infarction: a report from the Angina Pectoris-Myocardial Infarction Multicenter Investigators in Japan. Int J Cardiol. 2016; 207: 341-348, doi: 10.1016/j.ijcard.2016.01.188, indexed in Pubmed: 26820364.

15. Abreu G, Galvão Braga C, Costa J, et al. Spontaneous coronary artery dissection: A single-center case series and literature review. Rev Port Cardiol (Engl Ed). 2018; 37(8): 707-713, doi: 10.1016/j.repc.2017.07.019, indexed in Pubmed: 29935775.

16. Motreff $P$, Malcles $G$, Combaret $N$, et al. How and when to suspect spontaneous coronary artery dissection: novel insights from a single-centre series on prevalence and angiographic appearance. Eurolntervention. 2017; 12(18): e2236-e2243, doi: 10.4244/EIJ-D-16-00187, indexed in Pubmed: 27973331.

17. Nishiguchi T, Tanaka A, Ozaki Y, et al. Prevalence of spontaneous coronary artery dissection in patients with acute coronary syndrome. Eur Heart J Acute Cardiovasc Care. 2016; 5(3): 263-270, doi: 10.1177/2048872613504310, indexed in Pubmed: 24585938.

18. Inohara T, Saw J, Kohsaka S, et al. Treatment pattern and outcome of spontaneous coronary artery dissection in Japan. Int J Cardiol. 2020; 316: 13-18, doi: 10.1016/j.ijcard.2020.04.082, indexed in Pubmed: 32360646.

19. Saw J, Aymong E, Mancini GB, et al. Nonatherosclerotic coronary artery disease in young women. Can J Cardiol. 2014; 30(7): 814-819, doi: 10.1016/j. cjca.2014.01.011, indexed in Pubmed: 24726091.

20. De Roeck F, Scott B, Convens C, et al. Spontaneous coronary artery dissection in young female acute coronary syndrome patients: a single-centre retrospective cohort study. Acta Cardiol. 2020 [Epub ahead of print]: 1-5, doi: 10.1080/00015385.2020.1778373, indexed in Pubmed: 32552543.

21. Rashid HNZ, Wong DTL, Wijesekera $\mathrm{H}$, et al. Incidence and characterisation of spontaneous coronary artery dissection as a cause of acute coronary syndrome - a single-centre Australian experience. Int J Cardiol. 2016; 202: 336-338, doi: 10.1016/j.ijcard.2015.09.072, indexed in Pubmed: 26426273.

22. Meng PN, Xu C, You W, et al. Spontaneous coronary artery dissection as a cause of acute myocardial infarction in young female population: a single-center study. Chin Med J (Engl). 2017; 130(13): 1534-1539, doi: 10.4103/0366-6999.208245, indexed in Pubmed: 28639567.

23. Tweet MS, Hayes SN, Codsi E, et al. Spontaneous coronary artery dissection associated with pregnancy. J Am Coll Cardiol. 2017; 70(4): 426-435, doi: 10.1016/j.jacc.2017.05.055, indexed in Pubmed: 28728686.

24. Balakrishnan K, Scott P, Oliver L. A confluence of circumstances: a case of IVF, extreme exercise and spontaneous coronary artery dissection. Int J Cardiol. 2016; 203: 76-77, doi: 10.1016/j.ijcard.2015.10.099, indexed in Pubmed: 26495803.
25. Saw J, Humphries K, Aymong E, et al. Spontaneous coronary artery dissection: clinical outcomes and risk of recurrence. J Am Coll Cardiol. 2017; 70(9): 1148-1158, doi: 10.1016/j.jacc.2017.06.053, indexed in Pubmed: 28838364.

26. Saw J, Aymong E, Sedlak T, et al. Spontaneous coronary artery dissection: association with predisposing arteriopathies and precipitating stressors and cardiovascular outcomes. Circ Cardiovasc Interv. 2014; 7(5):645-655, doi: 10.1161/CIRCINTERVENTIONS.114.001760, indexed in Pubmed: 25294399.

27. Schifferdecker B, Pacifico L, Ramsaran EK, et al. Spontaneous coronary artery dissection associated with sexual intercourse. Am J Cardiol. 2004; 93(10): 1323-1324, doi: 10.1016/j.amjcard.2004.02.024, indexed in Pubmed: 15135719.

28. El-Sherief K, Rashidian A, Srikanth S. Spontaneous coronary artery dissection after intense weightlifting UCSF Fresno Department of Cardiology. Catheter Cardiovasc Interv. 2011; 78(2):223-227, doi: 10.1002/ccd.22904, indexed in Pubmed: 21413128.

29. Ijsselmuiden A, Verheye S. Cocaine-induced coronary artery dissection. JACC Cardiovasc Interv. 2009; 2(10): 1031, doi: 10.1016/j.jcin.2009.07.011, indexed in Pubmed: 19850267.

30. Afzal AM, Sarmast SA, Weber NA, et al. Spontaneous coronary artery dissection in a 22-year-old man on lisdexamfetamine. Proc (Bayl Univ Med Cent). 2015; 28(3): 367-368, doi: 10.1080/08998280.2015.11929277, indexed in Pubmed: 26130892.

31. Keir ML, Dehghani P. Corticosteroids and spontaneous coronary artery dissection: a new predisposing factor? Can J Cardiol. 2016; 32(3): 395. e7-395.e8, doi: 10.1016/j.cjca.2015.06.021, indexed in Pubmed: 26483092.

32. Zacher J, May E, Horlitz M, et al. Binge drinking alcohol with caffeinated "energy drinks", prolonged emesis and spontaneous coronary artery dissection: a case report, review of the literature and postulation of a pathomechanism. Clin Res Cardiol. 2018; 107(10): 975-979, doi: 10.1007/s00392-018-1262-y, indexed in Pubmed: 29728830.

33. Luong C, Starovoytov A, Heydari M, et al. Clinical presentation of patients with spontaneous coronary artery dissection. Catheter Cardiovasc Interv. 2017; 89(7): 1149-1154, doi: 10.1002/ccd.26977, indexed in Pubmed: 28244197.

34. Cheung CC, Starovoytov A, Parsa A, et al. In-hospital and long-term outcomes among patients with spontaneous coronary artery dissection presenting with ventricular tachycardia/fibrillation. Heart Rhythm. 2020; 17(11): 1864-1869, doi: 10.1016/j.hrthm.2020.06.019, indexed in Pubmed: 32590153

35. Phan D, Clare R, Duan L, et al. Characteristics and outcomes of patients with spontaneous coronary artery dissection who suffered sudden cardiac arrest. J Interv Card Electrophysiol. 2021;60(1): 77-83, doi: 10.1007/s10840019-00695-9, indexed in Pubmed: 32048115.

36. Tweet MS, Eleid MF, Best PJM, et al. Spontaneous coronary artery dissection: revascularization versus conservative therapy. Circ Cardiovasc Interv. 2014; 7(6): 777-786, doi: 10.1161/CIRCINTERVENTIONS.114.001659, indexed in Pubmed: 25406203.

37. Prakash R, Starovoytov A, Heydari M, et al. Catheter-induced iatrogenic coronary artery dissection in patients with spontaneous coronary artery dissection. JACC Cardiovasc Interv. 2016; 9(17): 1851-1853, doi: 10.1016/j.jcin.2016.06.026, indexed in Pubmed: 27609262.

38. Saw J. Coronary angiogram classification of spontaneous coronary artery dissection. Catheter Cardiovasc Interv. 2014; 84(7): 1115-1122, doi: 10.1002/ccd.25293, indexed in Pubmed: 24227590.

39. Lettieri C, Zavalloni D, Rossini R, et al. Management and long-term prognosis of spontaneous coronary artery dissection. Am J Cardiol. 2015; 116(1): 66-73, doi: 10.1016/j.amjcard.2015.03.039, indexed in Pubmed: 25937347.

40. Tweet MS, Hayes SN, Pitta SR, et al. Clinical features, management, and prognosis of spontaneous coronary artery dissection. Circulation. 2012; 126(5): 579-588, doi: 10.1161/CIRCULATIONAHA.112.105718, indexed in Pubmed: 22800851.

41. Saw JWL, Starovoytov A, Zhao Y, et al. Clinical predictors of recurrent dissection after spontaneous coronary artery dissection. J Am Coll Cardiol. 2017; 69(11): 273, doi: 10.1016/s0735-1097(17)33662-8.

42. Ten FM, Salazar CH, Perez-Vizcayno MJ, et al. P753 Feasibility and safety of intracoronary imaging in spontaneous coronary artery dissection. Eur Heart J. 2018; 39(Suppl 1), doi: 10.1093/eurheartj/ehy564.p753. 
43. Alfonso F, Paulo M, Gonzalo N, et al. Diagnosis of spontaneous coronary artery dissection by optical coherence tomography. J Am Coll Cardiol. 2012; 59(12): 1073-1079, doi: 10.1016/j.jacc.2011.08.082, indexed in Pubmed: 22421300.

44. Eleid MF, Tweet MS, Young PM, et al. Spontaneous coronary artery dissection: challenges of coronary computed tomography angiography. Eur Heart J Acute Cardiovasc Care. 2018; 7(7): 609-613, doi: 10.1177/2048872616687098, indexed in Pubmed: 28139136.

45. Tweet MS, Akhtar NJ, Hayes SN, et al. Spontaneous coronary artery dissection: Acute findings on coronary computed tomography angiography. Eur Heart J Acute Cardiovasc Care. 2019; 8(5): 467-475, doi: 10.1177/2048872617753799, indexed in Pubmed: 29376398.

46. Pozo-Osinalde E, García-Guimaraes M, Bastante T, et al. Characteristic findings of acute spontaneous coronary artery dissection by cardiac computed tomography. Coron Artery Dis. 2020; 31(3): 293-299, doi: 10.1097/MCA.0000000000000819, indexed in Pubmed: 31658141.

47. Prakash R, Starovoytov A, Aymong E, et al. Angiographic healing of spontaneous coronary artery dissection. J Am Coll Cardiol. 2017; 69(11): 231, doi: 10.1016/s0735-1097(17)33620-3.

48. Hassan S, Prakash R, Starovoytov A, et al. Natural history of spontaneous coronary artery dissection with spontaneous angiographic healing. JACC Cardiovasc Interv. 2019; 12(6): 518-527, doi: 10.1016/j.jcin.2018.12.011, indexed in Pubmed: 30826233.

49. Main A, Prakash R, Starovoytov A, et al. Characteristics of extension and de novo recurrent spontaneous coronary artery dissection. Eurolntervention. 2017; 13(12): e1454-e1459, doi: 10.4244/EIJ-D-17-00264, indexed in Pubmed: 28891472.

50. Main A, Saw J, et al. Percutaneous coronary intervention for the treatment of spontaneous coronary artery dissection. Interv Cardiol Clin. 2019; 8(2): 199-208, doi: 10.1016/j.iccl.2018.11.008, indexed in Pubmed: 30832942.

51. Kotecha D, Premawardhana A, Garcia-Guimaraes M, et al. Percutaneous coronary intervention in spontaneous coronary artery dissection: a case-control study. Eur Heart J. 2020; 41(Suppl 2), doi: 10.1093/ehjci/ehaa946.1523.

52. Lobo AS, Cantu SM, Sharkey SW, et al. Revascularization in patients with spontaneous coronary artery dissection and ST-segment elevation myocardial infarction. J Am Coll Cardiol. 2019; 74(10): 1290-1300, doi: 10.1016/j.jacc.2019.06.065, indexed in Pubmed: 31488265.

53. Mahmood MM, Austin D. IVUS and OCT guided primary percutaneous coronary intervention for spontaneous coronary artery dissection with bioresorbable vascular scaffolds. Cardiovasc Revasc Med. 2017; 18(1): 53-57, doi: 10.1016/j.carrev.2016.09.005, indexed in Pubmed: 27717579.

54. Osinalde EP, Macaya F, Camacho-Freire SJ, et al. Late results of bioabsorbable scaffolds implanted in spontaneous coronary artery dissection evaluated with computed tomography coronary angiography. Eur Heart J. 2020; 41(Suppl 2), doi: 10.1093/ehjci/ehaa946.1738.

55. Alkhouli M, Cole M, Ling FS. Coronary artery fenestration prior to stenting in spontaneous coronary artery dissection. Catheter Cardiovasc Interv. 2016; 88(1): E23-E27, doi: 10.1002/ccd.26161, indexed in Pubmed: 26333193.

56. Julià I, Tauron M, Muñoz-Guijosa C. Postpartum acute coronary syndrome due to intramural hematoma and coronary artery dissection. Thorac Cardiovasc Surg. 2013; 61(1): 85-87, doi: 10.1055/s-0032-1331152, indexed in Pubmed: 23161482.

57. Jorge-Pérez P, García-González MJ, Ávalos-Pinto RM, et al. Spontaneous coronary dissection and cardiogenic shock requiring mechanical circulatory support in a non-transplant center. Int J Cardiol. 2016; 221:629-630, doi: 10.1016/j.ijcard.2016.07.015, indexed in Pubmed: 27420590.

58. Páez M, Buisán F, Herrero E. Spontaneous dissection of the left coronary artery trunk during the postpartum period treated with revascularization surgery, ventricular assistance and a successful heart transplant. Acta Anaesthesiol Scand. 2007; 51(7): 960-961, doi: 10.1111/j.13996576.2007.01359.x, indexed in Pubmed: 17635409.

59. Al-Hussaini A, Abdelaty AM, Gulsin GS, et al. Chronic infarct size after spontaneous coronary artery dissection: implications for pathophysiology and clinical management. Eur Heart J. 2020; 41(23): 2197-2205, doi: 10.1093/eurheartj/ehz895, indexed in Pubmed: 31898721.

60. Franco $C$, Starovoytov $A$, Heydari $M$, et al. Changes in left ventricular function after spontaneous coronary artery dissection. Clin Cardiol. 2017; 40(3): 149-154, doi: 10.1002/clc.22640, indexed in Pubmed: 28218398.
61. Chou AY, Prakash R, Rajala J, et al. The first dedicated cardiac rehabilitation program for patients with spontaneous coronary artery dissection: description and initial results. Can J Cardiol. 2016; 32(4): 554-560, doi: 10.1016/j.cjca.2016.01.009, indexed in Pubmed: 26923234.

62. Bhatt DD, Kachru R, Gupta $S$, et al. Recurrent chest pain after treatment of spontaneous coronary artery dissection: an enigma. Indian Heart J. 2015; 67(Suppl 3): S18-S20, doi: 10.1016/j.ihj.2015.09.006, indexed in Pubmed: 26995421

63. Roura G, Ariza-Solé A, Rodriguez-Caballero IF, et al. Noninvasive follow-up of patients with spontaneous coronary artery dissection with $\mathrm{CT}$ angiography. JACC Cardiovasc Imaging. 2016; 9(7): 896-897, doi: 10.1016/j. jcmg.2015.06.011, indexed in Pubmed: 26476501.

64. Tweet MS, Gulati R, Williamson EE, et al. Multimodality imaging for spontaneous coronary artery dissection in women. JACC Cardiovasc Imaging. 2016; 9(4): 436-450, doi: 10.1016/j.jcmg.2016.01.009, indexed in Pubmed: 27056163.

65. Eleid MF, Guddeti RR, Tweet MS, et al. Coronary artery tortuosity in spontaneous coronary artery dissection: angiographic characteristics and clinical implications. Circ Cardiovasc Interv. 2014; 7(5): 656-662, doi: 10.1161/CIRCINTERVENTIONS.114.001676, indexed in Pubmed: 25138034.

66. Tweet MS, Olin JW. Insights into spontaneous coronary artery dissection: can recurrence be prevented? J Am Coll Cardiol. 2017; 70(9): 1159-1161, doi: 10.1016/j.jacc.2017.07.726, indexed in Pubmed: 28838365.

67. Ponikowski P, Voors AA, Anker SD, et al. 2016 ESC guidelines for the diagnosis and treatment of acute and chronic heart failure. Rev Esp Cardiol (Engl Ed). 2016; 69(12): 1167, doi: 10.1016/j.rec.2016.11.005, indexed in Pubmed: 27894487.

68. Collet JP, Thiele H, Barbato E, et al. ESC Scientific Document Group. 2020 ESC Guidelines for the management of acute coronary syndromes in patients presenting without persistent ST-segment elevation. Eur Heart J. 2021; 42(14): 1289-1367, doi: 10.1093/eurheartj/ehaa575, indexed in Pubmed: 32860058.

69. Ibanez B, James S, Agewall S, et al. ESC Scientific Document Group. 2017 ESC Guidelines for the management of acute myocardial infarction in patients presenting with ST-segment elevation: The Task Force for the management of acute myocardial infarction in patients presenting with ST-segment elevation of the European Society of Cardiology (ESC). Eur Heart J. 2018; 39(2): 119-177, doi: 10.1093/eurheartj/ehx393, indexed in Pubmed: 28886621.

70. Gornik HL, Persu A, Adlam D, et al. First International Consensus on the diagnosis and management of fibromuscular dysplasia. Vasc Med. 2019; 24(2): 164-189, doi: 10.1177/1358863X18821816, indexed in Pubmed: 30648921.

71. Pate GE, Lowe R, Buller CE. Fibromuscular dysplasia of the coronary and renal arteries? Catheter Cardiovasc Interv. 2005; 64(2): 138-145, doi: 10.1002/ccd.20246, indexed in Pubmed: 15678450.

72. Kok SN, Hayes SN, Cutrer FM, et al. Prevalence and clinical factors of migraine in patients with spontaneous coronary artery dissection. J Am Heart Assoc. 2018; 7(24): e010140, doi: 10.1161/JAHA.118.010140, indexed in Pubmed: 30561271

73. Warchol-Celinska E, Prejbisz A, Dobrowolski $P$, et al. Systematic and multidisciplinary evaluation of fibromuscular dysplasia patients reveals high prevalence of previously undetected fibromuscular dysplasia lesions and affects clinical decisions: the ARCADIA-POL study. Hypertension. 2020; 75(4): 1102-1109, doi: 10.1161/HYPERTENSIONAHA.119.13239, indexed in Pubmed: 32148126.

74. Prasad M, Tweet MS, Hayes SN, et al. Prevalence of extracoronary vascular abnormalities and fibromuscular dysplasia in patients with spontaneous coronary artery dissection. Am J Cardiol. 2015; 115(12): 1672-1677, doi: 10.1016/j.amjcard.2015.03.011, indexed in Pubmed: 25929580.

75. Etminan N, Brown RD, Beseoglu K, et al. The unruptured intracranial aneurysm treatment score: a multidisciplinary consensus. Neurology. 2015; 85(10): 881-889, doi: 10.1212/WNL.0000000000001891, indexed in Pubmed: 26276380.

76. Krittanawong C, Tweet MS, Hayes SE, et al. Usefulness of cardiac rehabilitation after spontaneous coronary artery dissection. Am J Cardiol. 2016; 117(10): 1604-1609, doi: 10.1016/j.amjcard.2016.02.034, indexed in Pubmed: 27055757.

77. Smaardijk VR, Mommersteeg PMC, Kop WJ, et al. Psychological and clinical characteristics of female patients with spontaneous coronary artery 
dissection. Neth Heart J. 2020; 28(9): 485-491, doi: 10.1007/s12471-02001437-7, indexed in Pubmed: 32500434.

78. Johnson AK, Hayes SN, Sawchuk C, et al. Analysis of posttraumatic stress disorder, depression, anxiety, and resiliency within the unique population of spontaneous coronary artery dissection survivors. J Am Heart Assoc. 2020; 9(9): e014372, doi: 10.1161/JAHA.119.014372, indexed in Pubmed: 32342736.

79. Turley TN, Theis JL, Sundsbak RS, et al. Rare missense variants in TLN1 are associated with familial and sporadic spontaneous coronary artery dissection. Circ Genom Precis Med. 2019; 12(4): e002437, doi: 10.1161/CIRCGEN.118.002437, indexed in Pubmed: 30888838.

80. Fahey JK, Williams SM, Tyagi $\mathrm{S}$, et al. The intercellular tight junction and spontaneous coronary artery dissection. J Am Coll Cardiol. 2018; 72(14): 1752-1753, doi: 10.1016/j.jacc.2018.07.040, indexed in Pubmed: 30261968.

81. Adlam D, Olson TM, Combaret N, et al. DISCO Consortium, CARDIoGRAMPlusC4D Study Group. Association of the PHACTR1/EDN1 genetic locus with spontaneous coronary artery dissection. J Am Coll Cardiol. 2019; 73(1): 58-66, doi: 10.1016/j.jacc.2018.09.085, indexed in Pubmed: 30621952.

82. Kathiresan S, Voight BF, Purcell S, et al. Myocardial Infarction Genetics Consortium, Wellcome Trust Case Control Consortium. Genome-wide association of early-onset myocardial infarction with single nucleotide polymorphisms and copy number variants. Nat Genet. 2009; 41(3): 334-341, doi: 10.1038/ng.327, indexed in Pubmed: 19198609.

83. Nikpay M, Goel A, Won HH, et al. A comprehensive 1,000 Genomes-based genome-wide association meta-analysis of coronary artery disease. Nat Genet. 2015; 47(10): 1121-1130, doi: 10.1038/ng.3396, indexed in Pubmed: 26343387.

84. Anttila V, Winsvold BS, Gormley P, et al. Genome-wide meta-analysis identifies new susceptibility loci for migraine. Nat Genet. 2013; 45(8): 912-917, doi: 10.1038/ng.2676, indexed in Pubmed: 23793025.

85. Debette S, Kamatani Y, Metso TM, et al. CADISP Group.Common variation in PHACTR1 is associated with susceptibility to cervical artery dissection. Nat Genet. 2015; 47(1):78-83, doi: 10.1038/ng.3154, indexed in Pubmed: 25420145.

86. Turley TN, O'Byrne MM, Kosel ML, et al. Identification of susceptibility loci for spontaneous coronary artery dissection. JAMA Cardiol. 2020; 5(8): 929-938, doi: 10.1001/jamacardio.2020.0872, indexed in Pubmed: 32374345 .
87. Saw J, Yang ML, Trinder M, et al. Million Veteran Program. Chromosome 1q21.2 and additional loci influence risk of spontaneous coronary artery dissection and myocardial infarction. Nat Commun. 2020; 11(1):4432, doi: 10.1038/s41467-020-17558-x, indexed in Pubmed: 32887874.

88. Carss KJ, Baranowska AA, Armisen J, et al. Spontaneous coronary artery dissection: insights on rare genetic variation from genome sequencing. Circ Genom Precis Med. 2020; 13(6): e003030, doi: 10.1161/CIRCGEN.120.003030, indexed in Pubmed: 33125268.

89. Tweet MS, Young KA, Best PJM, et al. Association of pregnancy with recurrence of spontaneous coronary artery dissection among women with prior coronary artery dissection. JAMA Netw Open. 2020; 3(9): e2018170, doi: 10.1001/jamanetworkopen.2020.18170, indexed in Pubmed: 32965500.

90. Canobbio MM, Warnes CA, Aboulhosn J, et al. American Heart Association Council on Cardiovascular and Stroke Nursing; Council on Clinical Cardiology; Council on Cardiovascular Disease in the Young; Council on Functional Genomics and Translational Biology; and Council on Quality of Care and Outcomes Research. Management of pregnancy in patients with complex congenital heart disease: a scientific statement for healthcare professionals from the American Heart Association. Circulation. 2017; 135(8): e50-e87, doi: 10.1161/CIR.0000000000000458, indexed in Pubmed: 28082385.

91. Faden M, Bottega N, Benjamin A, et al. A nationwide evaluation of spontaneous coronary artery dissection in pregnancy and the puerperium. Heart. 2016; 102(24): 1974-1979, doi: 10.1136/heartjnl-2016-309403.

92. Appleby $C E$, Barolet $A$, Ing $D$, et al. Contemporary management of pregnancy-related coronary artery dissection: a single-centre experience and literature review. Exp Clin Cardiol. 2009; 14(1): e8-e16, indexed in Pubmed: 19492033.

93. Elkayam U, Jalnapurkar S, Barakkat MN, et al. Pregnancy-associated acute myocardial infarction: a review of contemporary experience in 150 cases between 2006 and 2011. Circulation. 2014; 129(16): 1695-1702, doi: 10.1161/CIRCULATIONAHA.113.002054, indexed in Pubmed: 24753549.

94. Smilowitz NR, Gupta N, Guo Yu, et al. Acute myocardial infarction during pregnancy and the puerperium in the United States. Mayo Clin Proc. 2018; 93(10): 1404-1414, doi: 10.1016/j.mayocp.2018.04.019, indexed in Pubmed: 30031555.

95. Havakuk O, Goland S, Mehra A, et al. Pregnancy and the risk of spontaneous coronary artery dissection: an analysis of 120 contemporary cases. Circ Cardiovasc Interv. 2017; 10(3): e004941, doi: 10.1161/CIRCINTERVENTIONS.117.004941, indexed in Pubmed: 28302642. 